\title{
A Card-Sorting Probe of E-Banking Trust Perceptions
}

\author{
Tim French \\ Informatics Research Centre \\ University of Reading \\ Whiteknights \\ Reading, RG6 6AH, UK \\ $+441234400400$ \\ Tim.french@beds.ac.uk
}

\author{
Kecheng Liu \\ Informatics Research Centre \\ University of Reading \\ Whiteknights \\ Reading, RG6 6AH, UK \\ +44118378 8614 \\ k.liu@reading.ac.uk
}

\author{
Mark Springett \\ Interaction Design Centre \\ Middlesex University \\ The Burroughs, Hendon \\ London NW4 4BE, UK \\ +442084115015 \\ m.springett@mdx.ac.uk
}

\begin{abstract}
This paper investigates the issue of trust mediation in eBanking. The card sorting technique was used to probe factors influencing subjects' attitudes to alternative e-banking homepage designs. The subjects also provided their trust perceptions for the same sites. These were cross-referenced with constructs generated in the card-sort to investigate the relationship between tangible and intangible trust mediators, including the interplay between site design and usability. The study findings suggest that the degree of effectiveness of tangible factors, such as security policy and trust seals, may be subtly influenced by design phenomena related to usability. The findings are articulated using Gambetta's theory of trust within an e-banking context. These are mapped to the layers of a semiotic trust ladder.
\end{abstract}

\section{Categories and Subject Descriptors}

H5.2 [Information Interfaces and Presentation (e.g., HCI)]: User interfaces - theory and methods.

\section{General Terms}

Design, Security, Human Factors, Theory.

\section{Keywords}

Trust, e-banking, card sorting, usability, design.

\section{INTRODUCTION}

The term trust is often used rather loosely to refer to technologies as diverse as trusted protocols, modern methods of Public Key Cryptography and trusted information architectures [12]. Intangible trust is an equally diverse field, comprising psychological studies, formal mathematical and cognitive models of trust, as well as studies of trust formation as an emotional, intangible response to Computer based stimuli $[3,6]$. Previous studies, including [31] seek to characterise initial B2C trust consumer formation (i.e., the initial 30 seconds) as being driven by a set of purely affective heuristics. One aim of the present enquiry is to gather further evidence in support of the notion that initial consumer trust formation is driven by a

(C) Tim French, Kecheng Liu, Mark Springett, 2007

Published by the British Computer Society

People and Computers XXI-HCI... but not as we know it:

Proceedings of HCI 2007

Linden J. Ball, M. Angela Sasse, Corina Sas, Thomas C. Ormerod, Alan Dix, Peter Bagnall, and Tom McEwan (Editors) combination of affective and rational factors. The work of Regelsberger et al. [25, 26, 28] supports the notion that building trust within on-line service encounters is mediated not only by contextual properties (temporal, social and institutional embeddedness) but also by the actors' intrinsic properties (ability, internalized norms). In [27] a framework is elaborated that accounts for contextual and intrinsic properties and which serves to highlight the need for designers to better understand new ways of signaling these properties within e-service encounters. The specific aim of this paper is to investigate online consumer trust formation within UK e-banking from a signaling standpoint.

A number of previous studies have explored the applicability of signaling theory to $\mathrm{B} 2 \mathrm{C}$ e-commerce consumer trust perceptions. Studies such as [24] and [28] probed the influence of presentation media on $\mathrm{B} 2 \mathrm{C}$ consumer trust. For example, research reported in [28] has established that the use of audio and video presentation influence on-line consumer trust perceptions. More generally, it would seem that site designers wishing to ensure high levels of consumer trust should select video (as the optimal type of signaling representation), followed closely by audio. Research described in [25] and [28], has made an important breakthrough in our understanding of trust signaling as between trustee and trustor via an explication and development of the work of Gambetta $[1,10]$. Later, we present a semiotic trust ladder that can be seen as a generic conceptual framework within which empirical findings and trust models derived from a signaling approach can be instantiated.

Egger's MoTeC model [6] accounts for the empirical, pragmatic and semantic levels of e-service trust semiosis. Furthermore, his model is supported by extensive empirical findings based on user studies using the think aloud protocol, followed by trust questionnaires. We seek to offer a more finegrained analysis of the influence of low-level design features (signs) upon user trust perceptions using e-banking as a case example. The long term goal is to provide tools that can guide the design and evaluation of trustworthy B2C sites. In so doing we align our view of trust formation to Gambetta's generic trust game in which both the consumer and E-Service provider, exchange signs and signals of trust as between a trustor (the online consumer) and trustee (E-Service provider). The signs of trust exchanged typically comprise a mixture of intended and unintended meanings.

Meanings may or may not prove to be reliable indicators of hidden trust warranting properties (e.g., honesty, integrity). For example, studies of taxi drivers and their customers in New York and Belfast found that drivers were able to quickly identify the surface level trust signs and signals emitted by passengers (intentionally or unintentionally) and were able to infer hidden trust warranting properties [11]. They found, for 
example, that a passenger hailing a cab using one brand of newspaper associated that person as being trustworthy, irrespective of the 'pick up' location.

E-mediated trust determinants are highly variable. Indeed, a highly diverse body of work has examined differential trust perceptions of e-commerce sites across linguistic and cultural boundaries $[14,15,20]$. Related studies have established that consumer perceptions of on-line trust and credibility are often determined by a user's irrational, emotional response to site aesthetics and surface level signs $[9,18,19]$.

Previous studies have also examined the relationship between the surface level design of a website and on-line consumer trust formation. On-line trust is directly influenced by factors such as the site's navigation model, style, aesthetics, and branding $[4,7$, 8]. De Souza [4] points to the need for theories that can bring together consumers and e-service providers through the interface, and identifies semiotic engineering as a key step in the design and evaluation of tangible and intangible trust. In an E-Service context, these systems typically comprise B2C (Business to Consumer) e-commerce sites, Web-Services and emergent Grid Service platforms and their associated Human Computer Interface components.

\section{TRUST AS SIGN EXCHANGE}

An important type of player in a trust game is an opportunist, a person who is not only untrustworthy but also overtly manipulative. By manipulative, Gambetta [11] means a proactively deceptive individual who may be able to emit false signs of trust (at a low enough cost) so as to obtain a selfish benefit at the expense of a genuine player. The same individual may be an opportunist in one trust game and trustworthy in another, or they may be globally untrustworthy. In this context, it is important to provide a working definition of what is meant by a trustworthy person. Indeed, as Gambetta goes on to explain:

"In general we say a person trusts someone to do $X$ if she acts on the expectation that he will do $X$ when both know that two conditions obtain: if he fails to do $X$, she would have done better to act otherwise, and her acting in the way she does gives him a selfish reason not to do X" [11].

In any given trust game, there are not less than two participants, namely a trustor and a trustee. One type of trustee is a person driven by raw self-interest that leads him not to do $\mathrm{X}$ given any opportunity to do so. The other type, is a person who has trust making qualities that motivate an individual to resist the appeal of self-interest and instead to do X [1]. Thus, the trustor's primary dilemma is to determine which type of trustee they are dealing with, the 'bad' or the 'good' type [10], interpreting the available signs and signals (trust manifesta).

The costs associated with the emission of signs are discussed in more depth in [1]. A collection of signals and signs emitted by a player in a trust game is only deemed to be secure against mimicry if it is cheap enough for a genuine player to display, but too expensive for an opportunist mimic to display. Some signs of trust are essentially costless and are known as 'cues'. An example might be an 'honest look'. Such signs are neutral in the trust game since they are easily emitted. However, they are notoriously unreliable as signs of hidden trust warranting properties. In any event, one important duty of a genuine player in a trust game is to manage the signs of trust they choose to emit. This management process includes the duty and obligation to review the collection of signs with a view to making it more expensive for an opportunist to mimic the signs of trust. Some signs of trust are compromised through low cost emission by opportunists. Therefore, the genuine player (a trustworthy trustee) in a trust game must revisit their signs and either seek higher-cost alternatives or adopt means by which the signs cannot be acquired with ease.

In Gambetta's terms, the B2C trust game is one 'beset by mimicry'. For a service provider the 'game' involves emitting enough signs of trust to overcome a consumer's genuine fears. For an e-commerce consumer the aim is to engage in a trustworthy e-commerce transaction, and not fall victim to a 'scam'. This necessarily involves interpreting surface level signs correctly. The main parameters of the $\mathrm{B} 2 \mathrm{C}$ trust game are described in the following paragraphs.

A B2C consumer has an inner psyche that is non-verbal and cannot be directly probed. This psyche comprises intentions, motivations and prejudices that are ultimately unique to a given individual. Some of the properties of the inner psyche are trust warranting, but are not directly observable.

The inner psyche engages with the world via a social and cultural medium so as to engage in sign games. These are acts of human communication, which in the case of e-banking, may take the form of direct human-to-computer interaction, humanto-human communication (hearsay), or human to service provider communication (direct or indirect contact with the bricks and mortar business). The consumer engages with the surface level signs of trust that populate the B2C website. Some of these may be genuine signs, others may be false signs of trust. Some will have been placed there explicitly by a service provider so as to engender trust (such as a brand sign). Others may be accidental or convey unintended meanings. The service provider deliberately populates the site with signs that explicitly or implicitly reflect hidden trust warranting properties of the 'real' bricks and mortar business. In so doing, they may conform to industry norms, cultural norms or internal implicit organisational norms.

In real $\mathrm{B} 2 \mathrm{C}$ encounters, customers typically engage with sites during a series of phases. Any of these phases can be terminated by failures of trust signaling. Clearly, termination can also take place for heterogeneous reasons due to misinterpretation of dyadic customer-vendor dialogues. Fogg [9], for example, has probed large scale consumer reactions to surface level site signs. The study showed that users invest their trust in numerous aspects of a site at varying levels of engagement, as they proceed from the initial encounter stage towards goal completion. It is, therefore, useful to identify the following phases of a B2C service encounter, although these are clearly not to be regarded as being rigidly defined. Rather, the stages merge to form a complete customer journey. Trust failures often mean that a customer's journey is terminated prematurely. Obviously, the service provider needs to design a site in such a way that such failures are ameliorated or at least substantially reduced.

\section{STAGES OF TRUST FORMATION}

The three trust formation stages described below appear to be generally recognised as being normative parts of a user's online experience. Any failure points associated with trust are likely result in a consumer terminating the service encounter. The identified stages are:

\section{- Initial site encounter}

Initial consumer trust formation takes place from the moment the user is presented with the home-page of the site. At this early stage of a service encounter, the determinants of consumer trust might typically be expected to include: site branding, task initiators, price and promotions, look and feel, holistic 
perceptions of the organisation, reputation, business partners, services and products. Specific signs of credibility such as a site's telephone number, physical address may also be perceived. Typically, notions of "trust" are transient.

\section{- Site engagement}

As the user actually seeks to engage dynamically through the site's state space model their initial set of expectations of trust and site credibility will typically be either undermined or reinforced as they proceed from initial states towards their goal and sub-goals. The critical purchase point represents one crucial goal state that users must reach if the site is to be financially viable. Shallow engagement might typically be initiated during the first few minutes of an e-service encounter.

\section{- Fulfilment}

Delivery of goods and services needs to match user expectations. If they do not, then trust may well be undermined. Frequent consumer issues mentioned anecdotally in the popular press include substitution of goods (e-groceries) and the difficulty of arranging timely delivery of tangible goods via shipping intermediaries. These stages are identified in Figure 1.

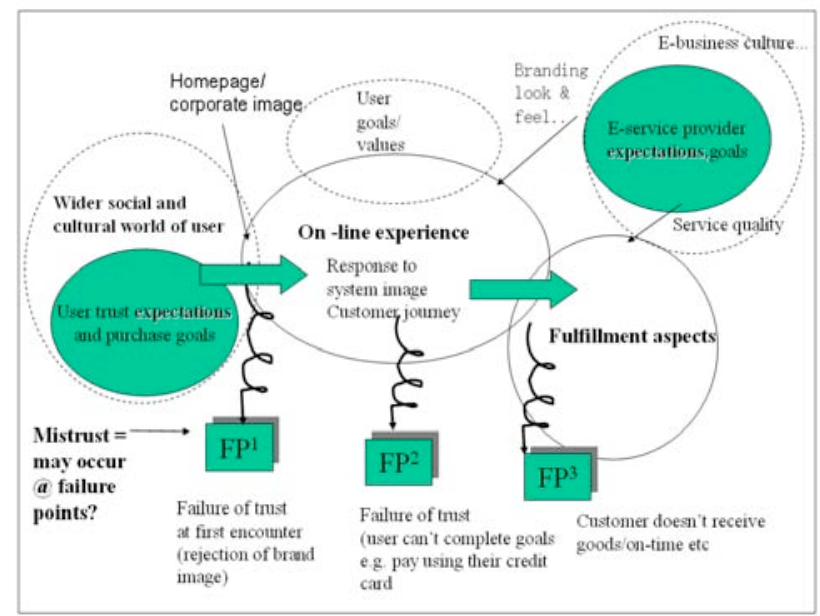

Figure 1. Stages of e-commerce trust formation.

We have developed a novel abstract trust ladder that shows how a typical e-service experience can be conceptualised into a series of layers, each contributing to consumer trust meaning making. The ladder is reproduced in Figure 2.

All interactive computer-based artefacts are meant to express a design vision according to an engineered signification system. By revealing the nuances of the signification system used in the design of meta-communication artefacts, and by mapping these to a semiotic ladder, it may be possible to produce designs that better match user expectations. The underlying notion of infinite semiosis rests on the idea that a sign is not just a simple relational structure. It does not merely bind together a representation and a mental interpretation triggered by that representation. Rather, it is a recursive function (which is in principle unlimited) in which interpretations become the argument for the next function application. Thus, the meaning for a fixed object or class of objects (e.g., trust signs) cannot be fixed or pre-determined in advance. The existence of a mental state directly determined by the presence of a representation, but only indirectly determined by the presence of an object, or class of objects, opens up the possibility of subjective phenomena interplaying with external phenomena, generating arbitrary interpretations for any given representation (e.g., a padlock sign embedded within a home page).
The design of an e-commerce website attends to tangible elements and strategic trust-orientated design elements, such as logo, branding, and the inclusion of pictures as interpersonal cues [24]. Previous work has considered the impact that such trust-building strategies have on trust formation, as well as secondary effects on interaction. Our current investigation considers both the efficacy of trust building strategies, but also the influence of factors that may not been seen as having any overt connection with trust building. In other words, part of the current investigation is to consider how sundry design features may become unintended 'interpersonal cues'.

\section{CARD-SORT PROBE OF E-BANKING HOME-PAGES}

\subsection{Motivation}

Our empirical investigations used the card-sorting technique to probe factors that contribute to consumer trust formation at the point when e-banking facilities are first encountered. This includes first encounters in the mirror of prior brand exposure, or simply first encounters with the brand. The reasoning is that a typical user population will include those with prior brand knowledge as well as those who are simply encountering the site through online search and competitor inspection. Card sorting was selected as the investigative approach because it can potentially reveal a user's multiple meaning making (decoding) of computer based trust signs at the home-page level at a finegrained level at an early stage in a design, or low fidelity artefact. This makes the technique particularly suitable for lowcost investigations of trust semiosis that can complement userbased studies. The constructs elicited, are rich enough to be useful in terms of eliciting feedback for designers, yet specific enough to both capture trust reactions to individual signs, groups of signs as well as holistic features.

The lightweight nature of the technique makes it an attractive and complementary tool to more familiar user-based studies. The approach taken targets trust perceptions rather than trust per se, as the subjects are not exposed to risk [26]. The aim of the study was to gather participants deep trust perceptions of signs embedded within example e-banking home-page settings.

Card sorting is an empirical investigative technique, originally conceived within the field of personal construct psychology [17]. The technique offers a means by which investigators can probe human cognition and meaning making, where the causation and sources of that personal meaning and categorisation of the world may be highly complex and diverse. The technique probes a subject's internal cognitive states, using an indirect investigative approach, revealing tacit or semi-tacit knowledge that the subject may be unable to articulate using a direct verbal questioning approach [21]. Card sorts have the additional advantage of relative ease in terms of time taken to develop, carry out and analyse [29].

Our contention is that designers may unintentionally generate 'signs' through design decisions that do no appear to explicitly relate to trust. Decisions about graphic style, the use of colours, choices about menu content and organisation, and navigation support, all potentially have consequences for trust formation. In other words, a design that follows the principles of good usability may fail because of negative deconstructions of meanings embodied in design aspects. We favour an approach that adds value to previous work by attempting to analyse the data derived from these indirect investigative approaches using a semiotic analytic frame of reference. 


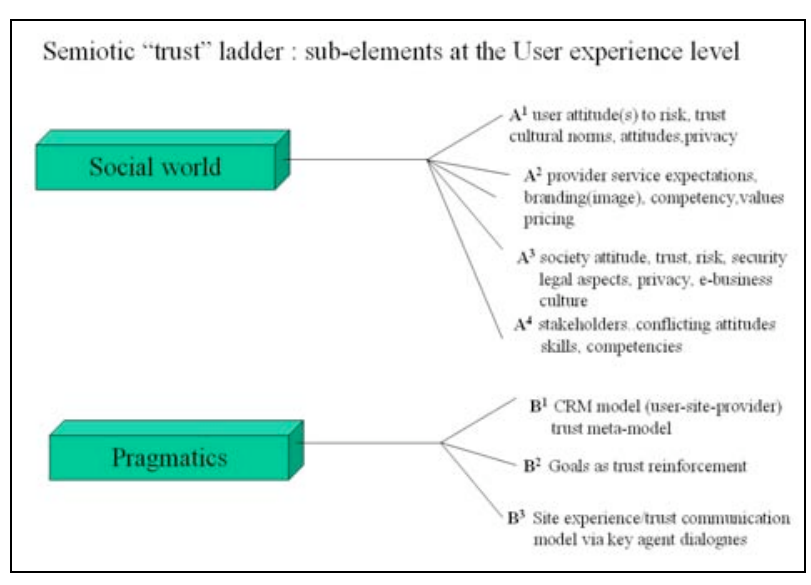

Semiotic "trust" ladder : sub-elements at the User experience level

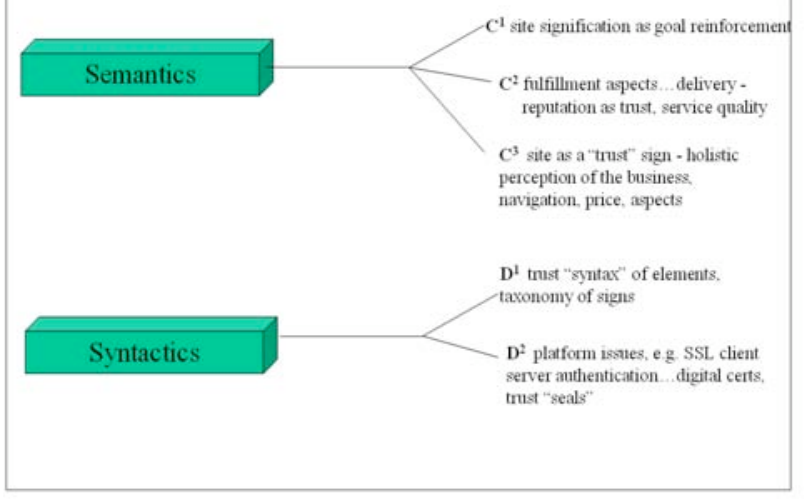

Figure 2. A semiotic trust ladder.

Semiotics has been called the 'science of signs'. More specifically, it is the discipline which connects meaning, meaning making, communication and culture through an understanding of acts of signification. There are a great variety of classical semiotic discourses and traditions, most noticeably that found in $[5,23,30]$. The fundamental notion of semiotics is that users give meanings to 'signs' through acts of signification (semiosis). This highly variable and subtle process, serves to mediate all acts of human communication via communication patterns, rituals, speech-acts, social constructs of various kinds. This meaning-making process influences our perceptions of computer based signs embedded in an interface. Semiosis is viewed as a potentially infinite process, often involving the assignment of multiple meanings to a given stimuli. Thus, a text (in our case an e-banking site) composed of signs, is created so as to transmit a set of meanings. These signs are then read and are assigned a set of meanings by human interpreters (consumers), within the context of an e-service encounter, and within the context of their own set of personal constructs.

\subsection{Method and Data Analysis}

The study used forty subjects between the ages of 25-40 of various nationalities ( 17 female subjects). The lower limit of 25 years was in deference to the fact that many people below that age may have limited engagement with products such as mortgages. The subjects responded to volunteer requests sent via e-mail. The oldest respondent was forty years of age. Ten subjects were post-graduate students and the remainder employees of Bedfordshire University. None of the subjects had bank accounts with any of the sites used in the study. The subjects were vetted for computer literacy. They were presented with cards showing static images of seven prominent UK-based e-banking website home pages presented on numbered cards: Abbey National, Egg, Nationwide, Intelligent Finance, MBNA, Royal Bank of Scotland, and Smile. E-Banking was selected since it is a relatively mature field (Nationwide was the first UK on-line banking site launched in 1997) that has been the subject of recent press attention in the context of mistrust (e.g., phishing attacks). Furthermore it is a field that has high utility (currently c.18 million UK citizens Bank on-line).

The subjects were asked to generate criteria (e.g., use of colour, presence of security information) and then asked to sort the cards into groups in accordance with their self-selected criteria, giving a brief description of why the grouped cards were considered similar (i.e., construct generation). The subjects performed this repeatedly, until they were unable to generate any further criteria. At this point they were asked to give an individual trust perception score to each site using a Likert scale. They were asked further questions designed to elicit their perception of the most significant factors influencing their trust perception score. The responses were analysed for evidence of subjects' interpretation of the home-page images, anticipation of the site as a whole, and their perceptions of the organisation.

\section{RESULTS}

\subsection{Overview}

A total of 135 criteria were captured from the 40 participants in the study. There was great variability between the subjects in terms of the number of criteria cited (2-23). Cards were generated from screen shots of the home-pages of seven prominent UK E-Banks during May 2006. Some of these criteria refer to the presence or absence of a fine-grained taxonomy. Computer-based signs include padlocks, Verisign, hypertext links, images, and promotions. Other criteria, refer to aspects of site design, branding and promotions. In Table 1 we have provisionally grouped the user-generated criteria into five sections. The criteria were grouped into categories so as to merge those that are deemed to be semantically equivalent. We followed the method adopted in [29] to established semantic equivalence between constructs. These preliminary categories form a convenient frame of reference within which to explore more finely detailed trust and distrust meaning making, as related to holistic site trust perceptions and subject responses to individual signs. The categorization identified the primary referent of the criteria. So, for example, 'visibility of security information' would be in the category of 'internal regulatory seals', whereas 'clarity of options' would be in the category 'design aspects'.

External trust seals are items of a general nature that are used to engender trust, such as the Verisign symbol and the padlock representing security. Internal regulatory seals, include the banks' own policy declarations, and corporate branding. The wide-ranging nature of the referenced phenomena demonstrates the differing ways in which the subjects are choosing to interpret the signs of trust embedded within the e-banking home-pages.

\subsection{External Trust Seals}

Two main items were cited, namely the Verisign seal, which was visible on only one of the seven pages, and the padlock item which was visible on three of the seven pages. Only ten subjects made reference to these features, citing concerns at their absence from the other four sites. Our findings support the 
work of [13] who gathered evidence to show that information from a trusted third party would not be effective if consumers either fail to notice them or misunderstand their meanings.

\subsection{Internal Regulatory Seals}

Six subjects made direct reference to some aspect of security, privacy or guarantee policy. Two of the six distinguished between present security information on the grounds of presentation. One of these dismissed three of the sites for placing Security and Privacy in substantial menu arrays. The subject generated the construct 'standard tags-just another feature' to describe the way that these were presented. This was in contrast to the other four sites which had more prominent security signs.

Table 1. Pre-grouped categories of cited criteria.

\begin{tabular}{|l|l|}
\hline Categories of criteria & Referenced phenomena \\
\hline $\begin{array}{l}\text { External trust seals/third } \\
\text { party accreditation }\end{array}$ & $\begin{array}{l}\text { Verisign, Padlocks, 'best } \\
\text { Internet bank' award. }\end{array}$ \\
\hline Internal regulatory seals & $\begin{array}{l}\text { Security information, Privacy } \\
\text { policy, legal policy, branding, } \\
\text { banking codes, guarantees, } \\
\text { policy on liability. }\end{array}$ \\
\hline Task-related content & $\begin{array}{l}\text { Interest rates, offers, products } \\
\text { and promotions, adverts, } \\
\text { support features for tasks. }\end{array}$ \\
\hline Design Aspects & $\begin{array}{l}\text { Graphic style, use of colour, } \\
\text { navigation support, page } \\
\text { layout, text style, overall } \\
\text { impression of appearance. }\end{array}$ \\
\hline Other & $\begin{array}{l}\text { Online only or high street } \\
\text { presence, contact information, } \\
\text { trustworthiness, customer } \\
\text { service facilities, planned } \\
\text { maintenance information. }\end{array}$ \\
\hline
\end{tabular}

These sites were labelled with the construct 'a sense that it matters'. A further subject made the distinction between sites displaying 'very visible' security information and 'present but not clear' information.

\subsection{Task-related content}

A total of nineteen criteria (from 12 of the subjects) made explicit reference to specific banking services. Of these, nine made reference simply to the content itself (e.g., good or bad rates of interest). One subject made reference to the degree of information provided, one to the degree of guidance, and four each to visibility and navigation. Two subjects praised three of the sites for providing extra devices for helping customers through the process (e.g., interest repayment calculators, demos) and contrasted this favourably with the 'standard information' of other sites. One subject added that it was a 'sign of commitment to the customer'. The same subject also used the construct 'combined with the corporate site', for one other site, claiming that this diminished the sense of customer care.

Other negative constructs declared included the degree of irrelevant advertising or features. Both were declared by one subject as suggesting that 'they want to fool me'.

\subsection{Design Aspects}

A total of forty-three criteria had design aspects as their primary referent. The vast majority of these were criteria referring directly to aesthetics/attractiveness, use of colour and or pictures, general screen layout, and to the sense of seriousness and professionalism conveyed. There was a strong correlation between the graphic design approach and the perceived degree of professionalism. Where professionalism was the cited criteria, or named under the other criteria as a construct, it was frequently contrasted against constructs such as 'frivolous', 'cartoonish', and 'inappropriate'. By contrast, constructs describing sites with fewer graphics and pictures, drew constructs such as 'clean', 'commercial' and 'appropriate'.

\section{TRUST PERCEPTION}

The subjects were asked to quantify their trust perceptions as expressed on a Likert scale (from -3 to +3 ). They were also given the opportunity to comment on the main motivation for their perceptions. These values were cross-referenced with membership of construct groups declared in the sorting exercise. Table 2 shows average Likert score per home page.

Table 2. Average trust scores per home page.

\begin{tabular}{|l|c|c|c|c|c|c|c|}
\hline Site & $\mathbf{1}$ & $\mathbf{2}$ & $\mathbf{3}$ & $\mathbf{4}$ & $\mathbf{5}$ & $\mathbf{6}$ & $\mathbf{7}$ \\
\hline $\begin{array}{l}\text { Mean } \\
\text { score }\end{array}$ & 0.22 & 1.28 & 0.83 & 2.54 & 1.97 & 2.65 & 0.18 \\
\hline
\end{tabular}

Site 1: (www.smile.co.uk) This site was criticised for providing too little information to engender trust. The absence of visible phone contact information (the bank is internet only) was cited as a reason. This reinforces findings reported by [9] in a study of e-commerce sites. The card sort data produced criticism of the site's sparse site layout, irrelevant advertising and voting, and the use of quotes from an 'unknown' source by way of recommendation.

Site 2: (www.egg.com) This site was criticised for 'gimmicky' graphics and described as being 'suspicious' by one subject who gave it a particularly low score. There was further criticism of its use of buzzwords and unfamiliar terms. This site had been cited by several subjects in the sorting exercise as being graphics heavy, and was also the subject of some negative constructs including 'inappropriate' and 'gimmicky' with reference to it's graphics, use of colours and 'degree of professionalism'. However, the sorts produced relatively good feedback for the site's clarity in terms of menus and information content.

Site 3: (www.if.com) This site was rated poorly by twelve subjects due to a 'cartoonish', 'not bank like' graphical presentation style, and was criticised as being 'difficult to take seriously' and 'like a kids site'. This site received relatively positive responses in the card sort exercise, and a mixed score for visibility and presence of its security and privacy information. One subject noted the contrast between a 'warm' invitation to apply for a mortgage and a 'harsh' repossession warning that accompanied it.

Site 4: (www.nw.co.uk) This site scored relatively strongly, and was praised for the visibility of, and emphasis upon its legal, privacy and security policy. However, lower scores from some subjects (who were not previously aware of the brand) were evident in response to a 'suspicious looking' human form in the centre of the screen. Nevertheless, the site had been generally 
described as 'clean' and 'professional looking' in the sorting exercise.

Site 5: (www.rbs.co.uk) This site was rated well for its 'clear layout' and 'professional' image, reflecting responses in the sorting exercises. There was however, a generally mixed reaction to its presentation of legal, privacy and security information. The site also received some criticism for having a high-profile mortgage offer, with a relatively low profile repossession warning.

Site 6: (www.abbey.co.uk) This site scored well with almost all subjects. The positive comments generally referred to the branding, trust seals and security policy. Some negative comments were made with reference to irrelevant graphics on the main screen area. One subject said that they 'felt a bit manipulated', and that it 'undermined the image', although this did not appear to have a significant negative influence on trust perception. This site was generally grouped positively for 'clear layout' and 'visibility of options'.

Site 7: (www.mbna.com) This site was given a particularly poor trust perception score. The image of the site received comments such as 'a mixture of serious and quirky', 'impersonal' 'looks just a money lender' and 'looks like an online shop'. The sorting exercise produced relatively negative responses to the site's form layout and displayed information. Subjects were asked to assign a trust score for each separate trust manifestum that they perceived. We calculated a trust score for each individual sign in the range: $[+3,+2 . .0,-1,-2,-3]$. Results derived from two visually contrasting sites (Nationwide, and If.com) are presented in Table 3. Space does not permit a comprehensive breakdown of all signs and sites. Individual signs clearly elicited widely differing reactions from the subjects. This shows that trust perceptions are related to fine grained site content and not simply the brand sign or simply their prior reputation.

Table 3. Trust sign manifesta scores.

\begin{tabular}{|l|c|c|}
\hline $\begin{array}{l}\text { Trust sign } \\
\text { (manifesta) }\end{array}$ & $\begin{array}{c}\text { Subjects who } \\
\text { noticed the } \\
\text { sign (n=43) }\end{array}$ & $\begin{array}{c}\text { Mean trust sign } \\
\text { scores } \\
\text { [max:+3,..0..min:-3] }\end{array}$ \\
\hline $\begin{array}{l}\text { Nationwide } \\
\text { Padlock sign }\end{array}$ & 10 & +1.8 \\
\hline $\begin{array}{l}\text { Nationwide brand } \\
\text { sign }\end{array}$ & 20 & +2.12 \\
\hline $\begin{array}{l}\text { Nationwide } \\
\text { "Fat man" } \\
\text { promotion }\end{array}$ & 9 & -1.44 \\
\hline $\begin{array}{l}\text { Nationwide } \\
\text { Traffic lights } \\
\text { ("planned } \\
\text { maintenance") }\end{array}$ & 7 & +0.42 \\
\hline $\begin{array}{l}\text { Nationwide } \text { Reg. } \\
\text { statement }\end{array}$ & 11 & +1.27 \\
\hline If.com brand sign & 22 & -0.45 \\
\hline $\begin{array}{l}\text { If.com "cartoon } \\
\text { graphics" }\end{array}$ & 22 & -0.40 \\
\hline
\end{tabular}

\section{ANALYSIS OF TRUST PROPAGATION}

Some site manifestum appear to be far more successful in engendering trust semiosis than others. Indeed, some signs act as positive signs of trust (e.g., the padlock sign), whilst others appeared to act as distrust reinforcers. For example, the human figure on the Nationwide site was variously dismissed as being 'disturbing' and 'suspicious' by some but not all subjects. In general, brand signs appear to be acting as successful trust manifesta for those banks with branch networks. This is consistent with an earlier study of banking trust [16]. Trust signs such as padlocks are cheap to emit, and appear to elicit positive reactions; even though there may be no link to any tangible form of security protocol (simply an image of a padlock does not supply security assurance). Paradoxically, third party seals such as Verisign trust seals, appear to be only weakly associated with positive trust perceptions. These are higher cost to emit, with a less beneficial outcome to an eservice provider. The reasons for this failure of trust transference remain unclear, but lack of recognition was cited by several subjects. A brand sign alone is not a successful trust manifestum or 'super' sign, since it is a necessary but not sufficient condition to evoke 'blind' consumer trust. Consumers are not 'fooled' by such signs and such signs do not appear to evoke 'blind' trust. Rather, it appears that brand signs only work if they are supported by a tangible embodiment instantiated in real bricks and mortar and a business reputation. Previous studies, including [22], support the idea that situational awareness can positively engender the trust of online banking consumers. Embodiment is a closely related (but more abstract) notion that may offer support for user's metal model formation. These results are broadly consistent with recent models of e-banking trust [2]. Attempts to make sites eye-catching by using cartoon images generally met with negative trust reactions, as compared to more formally structured sites (see Figure 3).

Consumers appear to be forming their trust perceptions by decoding clusters of manifesta (i.e., an aggregation of many different kinds of visual signs). The challenge for site designers is to determine the optimal mix that is likely to induce an overall positive reaction. Previous studies such as [24] and [32], support the notion that quite simple changes, such as embedding a photograph of a company's representative within an on-line Banking site can positively engender trust.

Consumers disliked the 'fat man' promotion, but still judged the Nationwide to be the most trustworthy site overall. Consumers disliked cartoons as a graphics style for e-banking. This 'trivial' style seemed to reinforce their already rather negative trust reactions to pure online banks. Clearly, trust semiosis is not atomic and remains a complex phenomenon. The mapping of trust manifesta to (hidden) trust warranting properties is shown in Table 4.

Positive and negative responses to particular elements of design were analysed for evidence of how the presentation of the home page had influenced subjects.

Table 5 below summarises links between cited aspects of design, negative constructs generated, and terms describing user interpretations. The constructs were identified either by remarks volunteered during the card-sort exercise or as elicited in the follow-up trust perception elicitation. The examples appear to show a link between presentational factors, affective reactions to presentation and negative trust propagation towards the site. This is consistent with the assertion that these design factors represent acts of signification, whether intended by the site designer or not. Clearly, some of the cited features such as the branding and the use of pictures were aimed at addressing the 'interpersonal dimension'. However, in other cases, it was notable that design considerations not typically associated with this dimension appeared to be influential. 

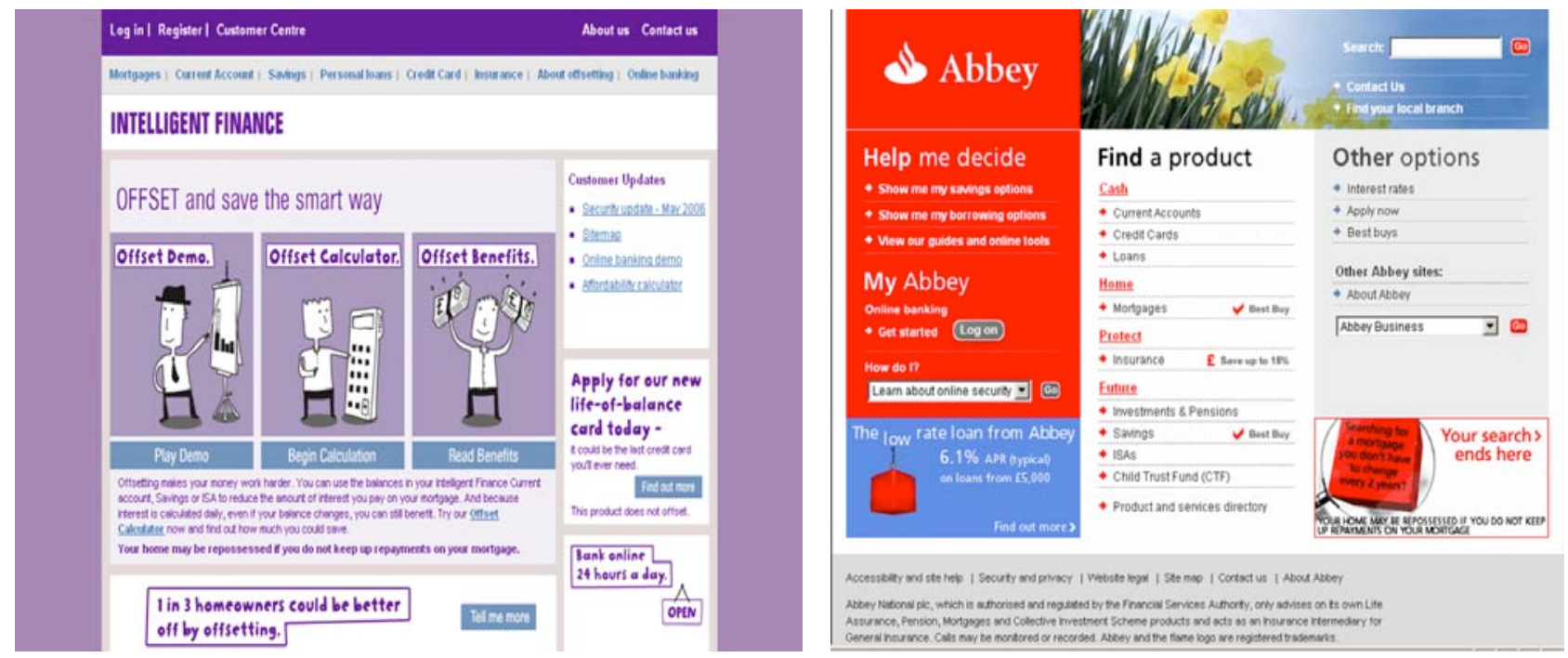

Figure 3. The 'cartoonish' look of the Intelligent Finance page contrasts with the 'professional' look of the Abbey site.

Table 4. Mapping trust manifesta to hidden trust-warranting properties.

\begin{tabular}{|l|l|l|l|}
\hline $\begin{array}{l}\text { Hidden trust warranting } \\
\text { property/trust ladder level }\end{array}$ & Related trust manifesta & Individual sign exemplars & User comments \\
\hline $\begin{array}{l}\text { Product/Service quality and } \\
\text { reliability } \\
\text { "QUALITY" [A2, B1] }\end{array}$ & $\begin{array}{l}\text { Graphics style and specific } \\
\text { product promotions and } \\
\text { service descriptions }\end{array}$ & $\begin{array}{l}\text { www.rbs.co.uk } \\
\text { "£500" cash-back offer } \\
\text { Cartoon images on } \\
\text { www.if.com home-page }\end{array}$ & $\begin{array}{l}\text { Promotion is "Too crude, not } \\
\text { credible"; } \\
\text { "hate cartoons, too simple/not } \\
\text { serious" }\end{array}$ \\
\hline $\begin{array}{l}\text { Secure site and products } \\
\text { tangibles) } \\
\text { "SECURITY" [D1, D2] }\end{array}$ & $\begin{array}{l}\text { Padlocks, SSL Verisign } \\
\text { seals, secure (https) log-in, } \\
\text { password }\end{array}$ & $\begin{array}{l}\text { www.if.com } \\
\text { Verisign SSL/TLS home page } \\
\text { security seal }\end{array}$ & $\begin{array}{l}\text { "Verisign Seal is not } \\
\text { recognized" }\end{array}$ \\
\hline $\begin{array}{l}\text { E-Service policies } \\
\text { "LOW RISK" [A1, A3] }\end{array}$ & $\begin{array}{l}\text { Money back if not } \\
\text { satisfied, on-line privacy } \\
\text { policies }\end{array}$ & $\begin{array}{l}\text { www.nationwide.co.uk } \\
\text { E-Service guarantee }\end{array}$ & - \\
\hline $\begin{array}{l}\text { Conformance to UK banking } \\
\text { regulations; } \\
\text { Branding/corporate governance } \\
\text { issues; peer rated awards } \\
\text { "TRUSTED BRAND / } \\
\text { GOVERNANCE" [A1, A3] }\end{array}$ & $\begin{array}{l}\text { Best on-line Bank award } \\
\text { of the year; Ethical } \\
\text { Banking }\end{array}$ & $\begin{array}{l}\text { www.smile.co.uk } \\
\text { Voted "Best Internet Bank" } \\
2005 \\
\text { www.rbs.co.uk }\end{array}$ & $\begin{array}{l}\text { "I don't recognize/know the } \\
\text { brand from the high street" }\end{array}$ \\
\hline
\end{tabular}

From a designer's perspective, the availability of components such as privacy and security may be sound, but there was evidence to suggest that this in itself may not be enough. Some of the sites criticized, had clear links to security and privacy features that would otherwise satisfy usability criteria. However, these features were seen by some as conveying a negative message about the organisation, the appearance of tokenism or lack of commitment. This suggests that trust factors influence key decisions about visual spacing clustering and prominence, factors that historically have been seen as more to do with straightforward cognitive ergonomics. The juxtaposition of a large, prominent mortgage offer and a small but terse repossession warning, conveyed conflicting messages and was seen as being visually too prominent and relatively unsupported by explicit trust and security statements, cues or guidance. Sites with visible security and privacy links in adequately prominent locations still caused some negative responses. Sites appearing to see security as just another feature' (typically sites where these links were displayed in a menu amongst several options) were deconstructed as conveying a relative lack of commitment to these key instrumental trust factors (see Figure 4). In these cases it is arguable that the established design principle of making the 'most important elements most prominent' is violated, not because of cognitive ergonomic factors, but because of the attitude that is conveyed. Therefore, 'importance' and the consequent need for prominence appear to be determined by affective factors.

\section{SUMMARY OF EMPIRICAL STUDY AND IMPLICATIONS FOR DESIGN}

The original assertion that both tangible and intangible factors influence consumer trust perception was supported by the constructs generated as well as by the more explicit links to trust perception revealed in the follow-up elicitation. Clearly, 
tangible factors such as external trust seals and security are influential and were cited heavily. Task-related content (the eservices) were frequently linked to usability issues such as navigation support and visibility of information and options. There was also evidence that intangible affective properties of the design influenced trust perception. For example, numerous subjects linked the apparent 'professionalism' mediated by the graphic design and style to their perceptions of the organisation. This suggests that designers' attempts to make such sites eyecatching, and carry the risk of undermining the seriousness of the bank's corporate image.

Table 5. Features and negative constructs (mistrust) - as affective and rational trust semiosis?

\begin{tabular}{|c|c|c|}
\hline $\begin{array}{l}\text { Feature } \\
\text { cited }\end{array}$ & $\begin{array}{l}\text { Negative } \\
\text { constructs }\end{array}$ & Example comments \\
\hline Graphics & $\begin{array}{l}\text { Gimmicky, cartoon- } \\
\text { like, irrelevant } \\
\text { [Affective] }\end{array}$ & $\begin{array}{l}\text { unprofessional, } \\
\text { inappropriate, } \\
\text { disturbing, suspicious. }\end{array}$ \\
\hline Text content & $\begin{array}{l}\text { Inconsistent, } \\
\text { buzzword-heavy, } \\
\text { irrelevant adverts, } \\
\text { irrelevant offers } \\
\text { [Affective] }\end{array}$ & $\begin{array}{l}\text { Suspicious, } \\
\text { patronizing. }\end{array}$ \\
\hline $\begin{array}{l}\text { Security/leg } \\
\text { al/ privacy } \\
\text { information }\end{array}$ & $\begin{array}{l}\text { Not sufficiently } \\
\text { emphasised } \\
\text { [Affective/rational] }\end{array}$ & 'don't appear to care'. \\
\hline Branding & $\begin{array}{l}\text { Poor reputation } \\
\text { [Rational] }\end{array}$ & 'crude marketing' \\
\hline $\begin{array}{l}\text { Products/ } \\
\text { services }\end{array}$ & $\begin{array}{l}\text { Unclear } \\
\text { lists/visibility } \\
\text { [Affective/rational] }\end{array}$ & $\begin{array}{l}\text { 'Not clear what's } \\
\text { being offered here' }\end{array}$ \\
\hline
\end{tabular}

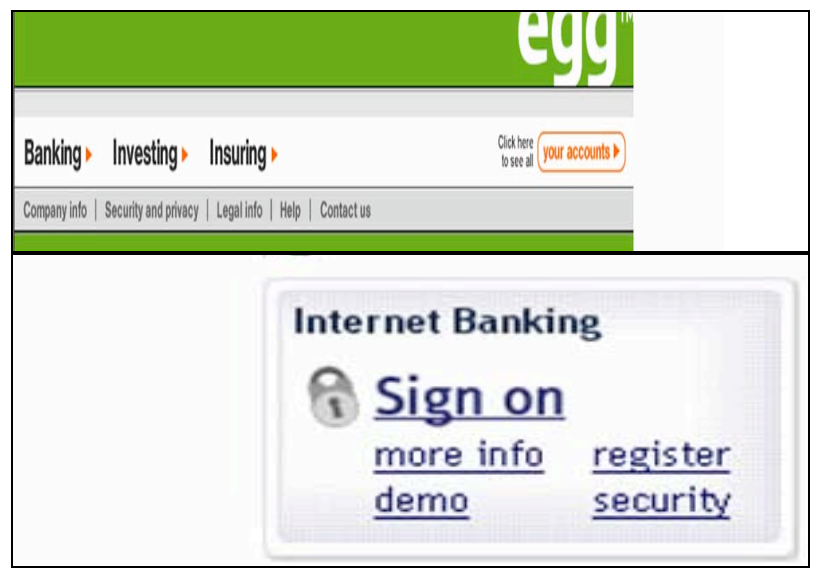

Figure 4. Contrasting approaches to displaying security.

Egg's menu option was compared unfavorably by some subjects to Nationwide's more prominent display.

Interestingly, a number of examples suggest that tangible and intangible factors are not always distinct from each other. It seems that aspects of design that mediate tangible factors may be deconstructed as positive or negative trust signs. In a number of examples, these design choices do not exactly violate usability principles, but the way that they are presented affects user attitudes.

\section{CONCLUSIONS AND FUTURE WORK}

Semiotic engineering views HCI as a particular case of computer-mediated human interaction [4]. The claim is that semiotics adds insights into the interpretation of metacommunication artefacts. In our study computer-based signs embedded within e-banking home-pages were decoded by subjects, in the form of personal constructs. These have successfully revealed trustors' responses to individual trust signs as well as to related features of the site's design. The study has demonstrated that the process of decoding surface level content may result in unintended meanings being decoded by subjects. By adopting the semiotic viewpoint it may be possible through further studies to predict more accurately the diverse ways in which users decode signs of trust and mistrust.

The longer term aim is to enable designers to utilise optimally the communication channel as between designer and user via the meta-communication artefact. Trust signalling is a field that has been as yet little explored in the specific context of live UK e-banking sites. Yet, it is one with both inherent complexity and commercial potential. We intend to probe beyond the homepage level in further work, so as to verify and build upon previous studies. A fine-grained model of trust signalling is presently under construction. It is hoped that this will encompass detailed sign taxonomies that will fully instantiate the semiotic ladder. Given the high utility of e-banking and the increasing criminal misuse of such sites, a better understanding of trust semiosis would appear to be useful, so that sites can engender consumer trust, and ameliorate valid consumer fears. This study has sought to make a small contribution to our understanding of this complex area.

\section{REFERENCES}

[1] Bacharach, M., and Gambetta, D. Trust in signs. In K. Cook (ed.), Trust in society. Russell Sage Foundation, New-York, 2001.

[2] Benamati, J., Serva, M. A., and Fuller, M. A. Are trust and distrust distinct constructs? An empirical study of the effects of trust and distrust among online banking users. In Proceedings of the 39th annual Hawaii international conference on System Sciences - Vol. 6. 2006.

[3] Corritore, C. L., Kracher, B., and Wiedenbeck, S. On-line trust: Concepts, evolving themes, a model. International Journal of Human Computer Studies, 58, 6 (2003), 737758 .

[4] De Souza, C. The Semiotic Engineering of the Human Computer Interface. MIT Press, Cambridge, MA, 2005.

[5] Eco, U. A Theory of Semiotics. Indiana University Press, Bloomington, IA, 1976.

[6] Egger, F. N. "Trust me, I'm an online vendor": Towards a model of trust for e-commerce system design. In $\mathrm{CHI}$ 2000: Extended abstracts of the SIGCHI conference on Human factors in computing systems. ACM Press, New York, NY, 2000, 101-102.

[7] Egger, F. From Interactions to Transactions: Designing the Trust Experience for Business-to-Consumer Electronic Commerce. Proefschrift, Ph.D. Thesis, Technical University Eindhoven, The Netherlands, 2003. 
[8] Fang, X., and Salvendy, G. Customer-centred rules for design of e-commerce web sites. Communications of the ACM, 46, 12 (2003), 332-336.

[9] Fogg, B. J., Marshall, J., Kameda, T., Solomon, J., Rangnekar, A., Boyd, J., and Brown, B. Web credibility research: A method for online experiments and early study results. In CHI 2001: Extended abstracts of the SIGCHI conference on Human factors in computing systems. ACM Press, New York, NY, 2001, 295-296.

[10] Gambetta, D. Can we trust trust? In D. Gambetta (ed.), Trust making and breaking co-operative relations. Blackwell, New York, 1988, 213-237.

[11] Gambetta, D., and Hamil, H. Streetwise: How Taxi Drivers Establish Customers' Trustworthiness. Russell Sage Publications, New-York, 2005.

[12] Grandison T., and Sloman, M., A survey of trust in internet applications. IEEE Communications and Surveys. Fourth Quarter 2000. Available as a PDF download from: http://www.comsoc.org/pubs/surveys

[13] Huang, L., Farn,C., and Yin, K. On initial trust building for e-commerce: Revisiting from the perspective of signal theory and trust transference. In Proceedings of the 13th european conference on Information systems. 2005. Available as a PDF download from: http://is2.1se.ac.uk/asp/aspecis/20050083.pdf

[14] Jarvenpass S., Tractinsky N., and Vitale M. Consumer trust in an internet store. Information Technology and Management Journal, 1, 1-2 (1999), 45-71.

[15] Karvonen, K. Designing trust for a universal audience: A multicultural study on the formation of trust in the internet in the nordic countries. In Proceedings of the 1st international conference on Universal access in $\mathrm{HCI}$ (UAHCI 2001). 2001.

[16] Kiefer, T. The future role of banks in electronic commerce: Trust as the critical factor of success in business enabling. In Proceedings of the $8^{\text {th }}$ European Conference on Information Systems. (Vienna, 2000). 2000, 886-874.

[17] Kelly, G. The Psychology of Personal Constructs. Norton and Co., Inc., USA, 1955.

[18] Kim, J., and Moon, J.Y. Designing towards emotional usability in customer interfaces--trustworthiness of cyberbanking system interfaces. Interacting with Computers, 10 , 1 (1998), 1-29.

[19] Lohse, J. Usability and profits in the digital economy. In People and Computers XIV (Proceedings of HCI 2000). Springer-Verlag, London, 2000, 3-16.

[20] Lundgren, H., and Walczuch, R. Moderated trust: The impact of power distance and uncertainty avoidance on the consumer trust formation process in e-retailing. In Proceedings of the tenth research symposium on Emerging electronic markets. (University of Bremen, 2000). 2000, 31-52.

[21] Maiden, N.A.M., and Rugg, G. ACRE: A framework for acquisition of requirements. Software Engineering, 11, 3, (1996), 183-192.

[22] Nilsson, M., Adams, A., and Herd, S. Building security and trust in online banking. In CHI 2005: Extended abstracts of the SIGCHI conference on Human factors in computing systems. ACM Press, New York, NY, 2005, 1701-1704

[23] Peirce, C. (ed. C. Hartshorne and P. Weiss). Collected Paper of C.S. Peirce. Harvard University Press, Cambridge, MA, 1960.

[24] Riegelsberger, J., Sasse, M. A., and McCarthy, J. Shiny happy people building trust? Photos on e-commerce websites and consumer trust. In Proceedings of the SIGCHI conference on Human factors in computing systems (CHI 2003). ACM Press, New York, NY, 2003, 121-128.

[25] Riegelsberger, J., Sasse, M. A., and McCarthy, J. Trust at first sight? A test of users' ability to identify trustworthy e-commerce sites. In People and Computers XVII (Proceedings of HCI 2003). Springer-Verlag, London, 2003, 243-259.

[26] Riegelsberger, J., Sasse, M. A., and McCarthy, J. The researcher's dilemma: Evaluating trust in computer mediated communications. International Journal of Human Computer Studies, 58 (2003), 759-781.

[27] Riegelsberger, J., Sasse, M. A., and McCarthy, J. The mechanics of trust: A framework for research and design International Journal of Human-Computer Studies, 62, 3 (2005), 381-422.

[28] Riegelsberger, J., Sasse, M. A., and McCarthy, J. Rich media, poor judgement? A study of media effects on users' trust in expertise. In People and Computers XIX (Proceedings of HCI 2005). Springer-Verlag, London, 2005, 267-284.

[29] Rugg, G., and Mc George, P. The sorting techniques: A tutorial paper on card sorts, picture sorts and item sorts. Expert Systems, 14, 2 (1997), 80-93.

[30] Saussure, F. Course in General Linguistics. Duckworth, New York, 1976

[31] Sillence, E, Briggs, P. Harris, P., and Fishwick, L. A framework for understanding trust factors in web-based health advice. International Journal of Human-Computer Studies, 64, 8 (2006), 697-713.

[32] Steinbruck, U., Schaumburg, H., Duda, S., and Kruger, T. A picture says more than a thousand words: Photographs as trust builders in e-commerce websites. In $\mathrm{CHI} 2002$ : Extended abstracts of the SIGCHI conference on Human factors in computing systems. ACM Press, New York, NY, 2002, 748-749. 